\title{
Construct validity and reliability of EQ-5D-3L for stroke survivors in a lower middle income setting
}

\author{
P K B Mahesh ${ }^{1}$, M W Gunathunga ${ }^{2}$, S Jayasinghe ${ }^{2}$, S M Arnold ${ }^{3}$, S Senanayake ${ }^{4}$, C Senanayake \\ L S D De Silva ${ }^{5}$, S Kularatna ${ }^{4}$
}

(Index words: EQ-5D-3L; quality of life; stroke; construct validity; Sri Lanka; SF-36)

\begin{abstract}
Introduction Stroke is a leading disease accounting for burden of chronic NCDs especially in lower and lowermiddle income (LMI) settings. Quality of Life (QOL) is considered as an important facet of determination of success of patient management. EQ-5D-3L is a generic QOL tool. It provides an index score amalgamating responses for five descriptive questions and a visual analogue scale (VAS) value.

Objectives To assess the validity and reliability of EQ5D-3L for stroke patients in Sri Lanka, which is a LMI setting.

Methods A descriptive cross sectional study was done among 100 stroke survivors among whom 50 each were managed at an ambulatory setting and an in-ward setting. A second wave of data collection was done for reliability analysis among one half of participants. The validity of EQ-5D-3L was assesses with five a-priori hypotheses. Reliability was assessed with test-retest method and with internal consistency. Non parametric Mann Whitney $\mathrm{U}$ test and Spearman correlation coefficients were used in the analysis.
\end{abstract}

Results The EQ-5D index scores had significant positive correlation with SF-36 domain scores $(p<0.001)$. The EQ-5D VAS scores had significant positive correlation with SF-36 domain scores $(\mathrm{p}<0.01)$. Index and VAS values of the EQ-5D were proved to be valid in known-group comparison $(p<0.001)$. Participants reporting some kind of impairment for EQ-5D-3L dimensions had lower SF-36 domain scores. All the kappa values in the analysis of test-retest method were significant $(p<0.001)$. For the VAS score, the Spearman correlation coefficient in testreter analysis was $0.993(p<0.001)$. Cronbach's alpha value was 0.928 .

Conclusions and Recommendations EQ-5D-3L questionnaire demonstrates construct validity and is a reliable tool in measuring QOL among stoke survivors in Sri Lanka.
Ceylon Medical Journal 2019; 64: 52-58

DOI: http://doi.org/10.4038/cmj.v64i2.8891

\section{Introduction}

Stroke is one of the main diseases accounting for global burden of chronic NCDs [1,2]. Globally 15 million experience strokes annually, out of which one third die and a similar number is left disabled [3]. As far as the lower and lower-middle income settings are concerned, stroke has become not only a health-related burden, but also a social and economic burden $[4,5]$.

Sri Lanka is a lower middle income country in the Indian Ocean, within which chronic NCDs account for half of the disability adjusted life years [6,7]. NCD burden in Sri Lanka is rising due to demographic and epidemiological transitions [6]. Hence it is expected that the incidence of stroke too would further rise in the future $[8,9]$. Stroke is regarded as the main cause of disability in Sri Lanka among the adults [8]. In Sri Lanka, stroke patients of acute stage are managed either in general medical wards or in specialized neurology wards. Later, they are followed up at clinic level or referred to a rehabilitation center for institutionalized care.

Quality of Life (QOL) is a composite concept of a person's subjective evaluation of their status of life. Hence, health related QOL is now considered as an important facet in evaluating the success of a stroke survivor [10]. An improvement of QOL of a patient is considered as an expected outcome of the management. The measurements of QOL could be done by using generic measurements as well as disease-specific measurements [11]. Out of these, the former category allows the comparisons related to QOL among different diseases [12]. Short-Form-36 and EQ-5D are two such generic measurements of QOL [13].

Out of the generic measures of QOL, the validity of SF-36 among stroke survivors has been explored in

${ }^{1}$ Melbourne School of Population and Global Health, University of Melbourne, ${ }^{2}$ Faculty of Medicine, University of Colombo, ${ }^{3}$ Office of Regional Director of Health Services, Colombo, ${ }^{4}$ Austalian Centre for Healh Services Innovation, Queensland University of Technology, ${ }^{5}$ Post Graduate Institute of Medicine, University of Colombo, Sri Lanka.

Correspondence: PKBM, e-mail: <buddhikamaheshpk@gmail.com>. Received 19 November 2018, revised version received 11 February 2019 and accepted 16 June 2019.

This is an open-access article distributed under the terms of the Creative Commons Attribution License, which permits unrestricted use, distribution, and reproduction in any medium, provided the original author and source are credited. 
Sri Lanka [14]. SF-36 consists of 36 questions covering eight scales and two summary measures [15]. The generic QOL tool called EQ-5D-3L consists of a descriptive system and a visual analogue scale. Levels of mobility, self-care, usual activities, pain and anxiety are included in the former. The output can be described as a health profile, health status which is self-rated and as an index value [16]. It has been used to measure QOL among patients with myocardial infarctions in Sri Lanka [17].

Validity of a tool reflects its ability to measure the parameter it is expected to measure [18]. There is no way to get a gold standard tool for QOL. Hence the second best option becomes construct validity. Convergent/divergent validity assessments and known group comparisons could be used in assessing the validity of a QOL tool [19]. Reliability reflects the reproducibility in relation to repeated measures of same concept. Reliability can be assessed with several ways including test-retest method and internal consistency [20].

Establishing the validity and reliability of a QOL tool on a disease condition would create more pathways in its utilization [19]. Since stroke is becoming a rising burden, assessing validity and reliability of a generic tool to measure QOL of stroke survivors would provide invaluable information for policy planner especially in lower and lowermiddle income settings. This study was done to assess the validity and reliability of EQ-5D-3L for stroke patients in Sri Lanka which is a lower middle income setting.

\section{Method}

\section{Selection of participants}

A descriptive cross sectional study was carried out at two settings; the rehabilitation unit of the Colombo North Teaching Hospital (CNTH) and the Neurology clinics of the National Hospital of Sri Lanka (NHSL) in January 2015. The former provides in-ward rehabilitation of the stroke survivors and the latter provides ambulatory care for patients after the discharge from the hospital. Documented evidence was used to ensure that participants were in par with the definition of World Health Organization which goes as "rapidly developing clinical signs of focal (or global) disturbance of cerebral function, with symptoms lasting 24 hours or longer or leading to death, with no apparent cause other than of vascular origin" [21]. Stroke survivors who were more than 16 years and within 28 days to 32 days of post-stroke period were included in inclusion criteria. The participants with lowered autonomy were excluded to ensure that proxy responses of the relatives were not taken.

In order to obtain reliable estimates, the number of observations should be 5 to 10 times that of the model being tested [22]. Since the questionnaire contained 6 variables (five descriptive questions and one on VAS score) it was decided to have more than 10 times of the number of variables. From the ambulatory group 50 survivors and from the hospital group 50 were selected.
The total sample size was thus 100. Data collection was done by the principal investigator and two trained data collectors who are MBBS qualified medical graduates awaiting the internship. The ambulatory group was approached by visiting the follow-up clinics of the Neurology Unit. The hospitalized group was approached by visiting the mentioned study setting. All initial interviews were conducted face-to-face. For the assessment of reliability, selected patients were contacted over the phone with permission.

\section{Study tools}

Interviewer-administered questionnaire was used which comprised of EQ-5D-3L and SF-36 questionnaires. SF-36 includes eight domains; role limitations caused by physical problems (4 items), physical function (10 items), role limitations caused by emotional problems (3 items), pain (2 items), social function (2 items), general health perceptions (5 items), emotional well-being (5 items) and energy / fatigue (4 items). Questions have different answer options which range from two to seven. While scoring, each question is scored in a scale ranging from 0 (worst health) to 100 (best health). All items in a domain are summed up and averaged to give an average score for each domain which ranges from 0 (worst health) to 100 (best health) [15].

The EQ-5D-3L instrument contains a descriptive component of five domains; mobility, self-care, usual activities, pain and anxiety. Each domain has one item and each item has three levels: one denoting no problems and three denoting severe problem. Thus, EQ-5D-3L has mutually exclusive 243 different health states. The linguistically-validated Sinhalese version of the EQ-5D3L was requested and obtained from the EuroQoL group. The index values of the EQ-5D-3L were calculated using the Sri Lanka specific value set derived by Kularatne et al (2014) [23]. Lower values indicate worse conditions, while 1.00 represents perfect health status. In addition it contains a visual analogue scale (VAS) ranging from 0 to 100 [16].

\section{Assessment of construct validity and reliability}

Construct validity were assessed using 5 a-priori hypotheses which were evaluated using the data gathered by SF-36.

I. The participants reporting some kind of impairment for EQ-5D-3L dimensions would have lower SF-36 domain scores

II. The EQ-5D index scores will have significant positive correlation SF-36 domain scores

III. The EQ-5D VAS scores will have a significant positive correlation with SF-36 domain scores

IV. The EQ-5D index values would be lower for the hospitalized group than the ambulatory group

V. The EQ-5D VAS scores would be lower for the hospitalized group than the ambulatory group 
This procedure is similar to the methodology adapted by Luo et al (2003) in evaluating the validity of the EQ-5D among patients with rheumatic diseases [22]. The index values of the EQ-5D-3L were calculated using the UKTTO value set with the permission of the EuroQol group.

Reliability was assessed by kappa analysis for the results of test-retest method among half of the participants on the same day after 12 hours. Furthermore internal consistency was checked with Cronbach's alpha. Ethics approval was obtained prior to data collection from the Medical Research Institute of Sri Lanka (Reference 60/2014) and informed written consent was obtained from the participants. Administrative permissions were obtained from the CNTH and NHSL.

\section{Results}

Figure 1 depicts the distribution of the EQ-5D scores. For the domains of mobility, selfcare and activity, the most common response was level 1 (i.e. no difficulty). For the pain and anxiety domains the commonest response was level 02 (i.e. having some difficulty).

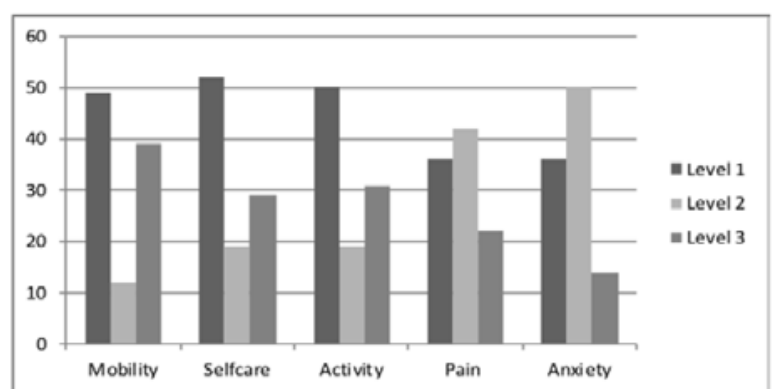

Figure 1. Distribution of responses for five EQ-5D descriptive questions.

The mean (SD) and the median (IQR) values of the EQ-5D Visual-Analogue-Scale (VAS) values were 64.67 (23.37) and 66.00 (50.00-84.00) respectively.

Table 1 summarizes the mean values of the 08 domains of SF-36, index value of EQ-5D and VAS value of EQ-5D while comparing the difference between the average values of the two healthcare settings.

Table 1. Distribution of SF-36 values and EQ-5D values among hospital and clinic patients

\begin{tabular}{|c|c|c|c|c|}
\hline Domain / Component & Total $(n=100)$ & Hospital $(n=50)$ & Clinic $(n=50)$ & $p$ value $^{+}$ \\
\hline \multicolumn{5}{|l|}{ General-health } \\
\hline -Mean (SD) & $57.4(16.4)$ & 52.0 (16.9) & 62.85 (14.23) & \multirow[t]{2}{*}{$\mathrm{p}=0.001$} \\
\hline -Median (IQR) & $55.0(50.0-65.0)$ & $50.0(40.0-61.0)$ & $60.0(55.0-66.3)$ & \\
\hline \multicolumn{5}{|l|}{ Physical-function } \\
\hline -Mean (SD) & $50.2(45.1)$ & $6.3(11.4)$ & $94.1(6.36)$ & \multirow[t]{2}{*}{$\mathrm{p}<0.001^{*}$} \\
\hline -Median (IQR) & $62.5(0.0-95.0)$ & $0.0(0.0-5.0)$ & $95.0(90.0-100.0)$ & \\
\hline \multicolumn{5}{|l|}{ Pain } \\
\hline -Mean (SD) & $53.4(346)$ & 23.1 (18.9) & $83.8(13.7)$ & \multirow[t]{2}{*}{$\mathrm{p}<0.001^{*}$} \\
\hline -Median (IQR) & $65.0(22.5-87.5)$ & $22.5(10.0-32.5)$ & $87.5(77.5-92.5)$ & \\
\hline \multicolumn{5}{|l|}{ Role-limitation-physical } \\
\hline -Mean (SD) & $47.4(45.3)$ & $6.0(16.4)$ & $88.8(19.4)$ & \multirow[t]{2}{*}{$\mathrm{p}<0.001^{*}$} \\
\hline -Median (IQR) & $50.0(0.0-100.0)$ & $0.0(0.0-0.0)$ & $100.0(75.0-100.0)$ & \\
\hline \multicolumn{5}{|c|}{ Role-limitation-emotional } \\
\hline -Mean (SD) & $48.2(45.2)$ & $10.0(24.3)$ & 86.3 (23.7) & \multirow{2}{*}{$\mathrm{p}=0.001^{*}$} \\
\hline -Median (IQR) & $50.0(0.0-100.0)$ & $0.0(0.0-0.0)$ & $100.0(66.7-100.0)$ & \\
\hline \multicolumn{5}{|l|}{ Vitality } \\
\hline -Mean (SD) & $57.2(19.9)$ & $46.4(19.8)$ & $67.9(13.2)$ & \multirow{2}{*}{$\mathrm{p}<0.001$} \\
\hline -Median (IQR) & $60.0(45.7-70.8)$ & $50.0(27.5-62.5)$ & $70.0(60.0-77.5)$ & \\
\hline \multicolumn{5}{|l|}{ Social-functioning } \\
\hline -Mean (SD) & $61.6(33.0)$ & $35.0(25.1)$ & $88.2(11.1)$ & \multirow[t]{2}{*}{$\mathrm{p}<0.001$} \\
\hline -Median (IQR) & $75.0(25.0-87.5)$ & $25.0(12.5-50.0)$ & 87.5 (75.0-100.5) & \\
\hline \multicolumn{5}{|l|}{ Mental-health } \\
\hline -Mean (SD) & $60.1(16.8)$ & $52.0(17.7)$ & 68.08 (11.38) & \multirow[t]{2}{*}{$\mathrm{p}<0.001^{*}$} \\
\hline -Median (IQR) & $60.0(50.0-72.0)$ & $52.0(40.0-64.0)$ & $68.0(60.0-76.0)$ & \\
\hline \multicolumn{5}{|l|}{ EQ-5D index } \\
\hline -Mean (SD) & $0.37(0.59)$ & $-0.45(0.40)$ & $0.87(0.11)$ & \multirow[t]{2}{*}{$\mathrm{p}<0.001$} \\
\hline -Median (IQR) & $0.64(-0.17,0.85)$ & $-0.65(-.43,0.02)$ & $0.81(0.79-1.00)$ & \\
\hline \multicolumn{5}{|l|}{ EQ-5D VAS } \\
\hline -Mean (SD) & $50.0(22.14)$ & $79.61(12.76)$ & $64.7(23.4)$ & \multirow[t]{2}{*}{$\mathrm{p}<0.001^{*}$} \\
\hline -Median (IQR) & $50.0(39.5-60.0)$ & $80.0(70.0-90.0)$ & $66.0(50.0-84.0)$ & \\
\hline
\end{tabular}

${ }^{+}$Mann-Whitney U test *Significant 
All domains showed a significant difference between the two settings with relatively higher values been observed for the ambulatory group.

Table 2 shows the Spearman correlation of the SF-36 scores with EQ-5D index score and the VAS value. All the eight of SF-36 have a significant relationship with the index value as well as the VAS value of EQ-5D. Out of these physical function, pain and social role-limitation-physical show a greater strength of association with the index as well as the VAS scores.

Table 2. Spearman correlation coefficients of SF-36 domain scores versus index value and VAS of EQ-5D with domains of SF-36

\begin{tabular}{lll}
\hline Domain of SF-36 & $\begin{array}{l}\text { EQ-5D } \\
\text { Spearman rho } \\
(\mathrm{p} \text { value })\end{array}$ & $\begin{array}{l}\text { EQ-VAS } \\
\text { Spearman rho } \\
(\mathrm{p} \text { value })\end{array}$ \\
\hline General Health & $\begin{array}{l}(\mathrm{p}<0.001)^{*} \\
\text { Physical-function }\end{array}$ & $\begin{array}{l}0.296 \\
(\mathrm{p}=0.003)^{*}\end{array}$ \\
Pain & $\begin{array}{l}(\mathrm{p}<0.001)^{*} \\
\text { Role-physical-limitation }\end{array}$ & 0.634 \\
& 0.839 & $(\mathrm{p}<0.001)^{*}$ \\
$(\mathrm{p}<0.001)^{*}$ & 0.608 \\
Role-emotional-limitation & 0.828 & $(\mathrm{p}<0.001)^{*}$ \\
& $(\mathrm{p}<0.001)^{*}$ & 0.605 \\
Vitality & 0.803 & $(\mathrm{p}<0.001)^{*}$ \\
& $(\mathrm{p}<0.001)^{*}$ & 0.591 \\
Social-functioning & 0.607 & $(\mathrm{p}<0.001)^{*}$ \\
& $(\mathrm{p}<0.001)^{*}$ & 0.486 \\
Mental-health & 0.789 & $(\mathrm{p}<0.001)^{*}$ \\
& $(\mathrm{p}<0.001)^{*}$ & 0.581 \\
& 0.529 & $(\mathrm{p}<0.001)^{*}$ \\
$(\mathrm{p}<0.001)^{*}$ & 0.507 \\
\hline
\end{tabular}

*Significant association

Table 3 shows the association between the five dimensions of EQ-5D with the SF-36 domains. In all the five dimensions, a significant difference was detected between "no problem" (i.e. Level 1) and "some-or-extreme problem" (Levels 2 and 3) categories in relation to SF-36 domain scores.

Table 3. Association between the SF-36 domain scores and EQ-5D impairment levels

\begin{tabular}{|c|c|c|c|c|c|c|c|c|}
\hline \multirow[t]{2}{*}{ Domain in EQ-5D } & \multicolumn{8}{|c|}{ SF-36 domains } \\
\hline & GH & $P F$ & $P N$ & $R L P$ & $R L E$ & $S F$ & $V T$ & $E M$ \\
\hline \multicolumn{9}{|l|}{ Mobility } \\
\hline \multicolumn{9}{|l|}{ Level 1} \\
\hline -Mean & $63.1^{*}$ & $92.8^{*}$ & $86.5^{*}$ & $86.6^{*}$ & $84.0^{*}$ & $86.5^{*}$ & $68.2^{*}$ & $67.7^{*}$ \\
\hline -Median & 60.0 & 95.0 & 87.5 & 100.0 & 100.0 & 87.5 & 70.0 & 68.0 \\
\hline \multicolumn{9}{|l|}{ Level 2-3 } \\
\hline -Mean & 52.0 & 9.3 & 25.0 & 9.8 & 13.7 & 37.7 & 46.5 & 52.7 \\
\hline -Median & 50.0 & 0.0 & 22.5 & 0.0 & 0.0 & 37.5 & 50.0 & 56.0 \\
\hline \multicolumn{9}{|l|}{ Self-care } \\
\hline \multicolumn{9}{|l|}{ Level } \\
\hline -Mean & $62.5^{*}$ & $92.0^{*}$ & $82.4^{*}$ & $87.3^{*}$ & $84.0^{*}$ & $86.8^{*}$ & $66.8^{*}$ & $67.8^{*}$ \\
\hline -Median & 60.0 & 95.0 & 87.5 & 100.0 & 100.0 & 87.5 & 70.0 & 68.0 \\
\hline \multicolumn{9}{|l|}{ Level 2-3 } \\
\hline -Mean & 52.0 & 4.9 & 22.1 & 4.2 & 9.4 & 34.4 & 46.7 & 52.0 \\
\hline -Median & 50.0 & 0.0 & 22.5 & 0.0 & 0.0 & 25.0 & 50.0 & 54.0 \\
\hline
\end{tabular}




\begin{tabular}{|c|c|c|c|c|c|c|c|c|}
\hline \multirow[t]{2}{*}{ Domain in EQ-5D } & \multicolumn{8}{|c|}{ SF-36 domains } \\
\hline & $G H$ & $P F$ & $P N$ & $R L P$ & $R L E$ & $S F$ & $V T$ & $E M$ \\
\hline \multicolumn{9}{|l|}{ Activity } \\
\hline \multicolumn{9}{|l|}{ Level 1} \\
\hline -Mean & $62.5^{*}$ & $89.2^{*}$ & $80.0^{*}$ & $84.3^{*}$ & $84.3^{*}$ & $89.0^{*}$ & $67.2^{*}$ & $67.0^{*}$ \\
\hline -Median & 60.0 & 95.0 & 83.8 & 100.0 & 100.0 & 87.5 & 67.5 & 68.0 \\
\hline \multicolumn{9}{|l|}{ Level 2-3 } \\
\hline -Mean & 52.4 & 11.2 & 26.9 & 10.5 & 12.0 & 34.2 & 46.8 & 53.1 \\
\hline -Median & 50.0 & 2.5 & 22.5 & 0.00 & 0.00 & 25.0 & 50.0 & 56.0 \\
\hline \multicolumn{9}{|l|}{ Pain } \\
\hline \multicolumn{9}{|l|}{ Level 1} \\
\hline -Mean & $63.8^{* *}$ & $92.6^{*}$ & $87.4^{*}$ & $88.4^{*}$ & $85.2^{*}$ & $88.2^{*}$ & $70.4^{*}$ & $68.6^{*}$ \\
\hline -Median & 60.0 & 100.0 & 90.0 & 100.0 & 100.0 & 87.5 & 70.0 & 72.0 \\
\hline \multicolumn{9}{|l|}{ Level 2-3 } \\
\hline -Mean & 53.8 & 26.3 & 34.3 & 24.3 & 27.3 & 46.7 & 49.8 & 55.3 \\
\hline -Median & 55.0 & 5.0 & 22.5 & 0.0 & 0.0 & 37.5 & 50.0 & 60.0 \\
\hline \multicolumn{9}{|l|}{ Emotional well-being } \\
\hline \multicolumn{9}{|l|}{ Level 1} \\
\hline -Mean & $62.8^{* * *}$ & $78.1^{*}$ & $79.6^{*}$ & $75.0^{*}$ & $76.9^{*}$ & $81.6^{*}$ & $68.7^{*}$ & $69.6^{*}$ \\
\hline -Median & 60.0 & 95.0 & 87.5 & 100.0 & 100.0 & 87.5 & 67.5 & 72.0 \\
\hline \multicolumn{9}{|l|}{ Level 2-3 } \\
\hline -Mean & 54.4 & 34.5 & 38.7 & 31.9 & 32.0 & 50.4 & 50.5 & 54.7 \\
\hline -Median & 55.0 & 5.0 & 22.5 & 0.0 & 0.0 & 54.0 & 54.0 & 56.0 \\
\hline
\end{tabular}

"Statistically significant at $\mathrm{p}<0.001,{ }^{* *}$-at $\mathrm{p}<0.01,{ }^{* * *}$-at $\mathrm{p}<.05$ level by Mann-Whitney U test, GH-general health, PF-physical-functioning, PN-pain, RLP-role-limitationphysical, RLE-role-limitation-emotional, SF-social-functioning, VT-vitality, EM-Emotional-health

Table 4 shows the reliability analysis done with test-retest method for categorical variables of ED-5D-3L tool. It shows that all kappa values were statistically significant.

Table 4. Kappa analysis of the categorical questions of EQ-5D-3L

\begin{tabular}{|c|c|c|c|c|c|c|}
\hline \multirow[b]{2}{*}{$2^{\text {nd }}$ round } & \multicolumn{5}{|c|}{ EQ-5D-3L descriptive questions- $1^{\text {st }}$ round responses } & \multirow[b]{2}{*}{ No.5 } \\
\hline & & No.1 & No.2 & No.3 & No.4 & \\
\hline \multirow[t]{2}{*}{ No.1 } & kappa & 1.000 & 0.709 & 0.508 & 0.608 & 0.327 \\
\hline & $\mathrm{p}$ value & $<0.001^{*}$ & $<0.001^{*}$ & $<0.001^{*}$ & $<0.001^{*}$ & $<0.001^{*}$ \\
\hline \multirow[t]{2}{*}{ No.2 } & kappa & 0.709 & 1.000 & 0.665 & 0.628 & 0.379 \\
\hline & $\mathrm{p}$ value & $<0.001^{*}$ & $<0.001^{*}$ & $<0.001^{*}$ & $<0.001^{*}$ & $<0.001^{*}$ \\
\hline \multirow[t]{2}{*}{ No.3 } & kappa & 0.471 & 0.631 & 0.966 & 0.504 & 0.414 \\
\hline & $\mathrm{p}$ value & $<0.001^{*}$ & $<0.001^{*}$ & $<0.001^{*}$ & $<0.001^{*}$ & $<0.001^{*}$ \\
\hline \multirow[t]{2}{*}{ No.4 } & kappa & 0.555 & 0.628 & 0.440 & 0.804 & 0.417 \\
\hline & $\mathrm{p}$ value & $<0.001^{*}$ & $<0.001^{*}$ & $<0.001^{*}$ & $<0.001^{*}$ & $<0.001^{*}$ \\
\hline \multirow[t]{2}{*}{ No.5 } & kappa & 0.387 & 0.446 & 0.414 & 0.494 & 0.934 \\
\hline & $\mathrm{p}$ value & $<0.001^{*}$ & $<0.001^{*}$ & $<0.001^{*}$ & $<0.001^{*}$ & $<0.001^{*}$ \\
\hline
\end{tabular}

Cronbach's alpha value was 0.928 . The spearman correlation coefficient VAS scores of the test-retest analysis was 0.993 ( $<<0.001)$. 


\section{Discussion}

The study proved that EQ-5D-3L is a valid generic QOL tool to be used among stroke survivors by using five a-prori hypotheses. Additionally it proved that EQ-5D-3L is a reliable tool by the test-retest methodology. This creates more opportunities for the utilization of EQ-5D-3L and hence certifies the applicability of a generic QOL tool for the stroke survivors.

Stroke survivors were selected to validate this due to several reasons. Firstly the SF-36 has been validated for stroke survivors in Sri Lanka [14]. The convergent/ divergent validity of EQ-5D was planned to be tested with SF-36. This enabled getting more valid comparisons. Secondly, two sub-populations were needed to be identified for known group comparison. Since stroke survivors are managed at institutional level as well as at the ambulatory level, this enabled the testing of above ability.

All other seven domains in SF-36 showed a significantly lower QOL scores in the institutionalized group compared to the ambulatory group. SF-36 being a validated tool for the local setting thus proved that the two groups were significantly different in relation to their QOLs. It is believed that the QOL among the ambulatory group is higher as their disability levels are expected to be lower. This would have affected the physical domains directly and the mental and social domains indirectly. The same findings have been obtained for the EQ-5D index and the VAS scores. This proves the ability of the EQ-5D in discriminating between two groups whose variables are expected to be different.

As there is no gold-standard test for QOL, evaluating the association with already validated tool becomes the best option for validation of EQ-5D-3L. SF-36 is an already validated tool for stroke survivors, which is a commonlyused generic measure that covers all domains approximately similar to that of EQ-5D. All the eight domain scores of the SF-36 had significant associations with the index value and the VAS score of EQ-5D. This is more or less comparative to the findings of Myers and Wilks (1999), who found that EQ-5D index scores and VAS score strongly correlate with SF-36 domain scores except for physical-role-limitation [23].

The individual domains were evaluated with the nonparametric Mann-Whitney U test. This method of analysis was are in par with the method and findings of Luo et al (2003) who validated it for Chinese-speaking patients with Rheumatic Diseases in Singapore [22]. Yet in this study, all the domains showed a significant difference between "no problem" and "some-or-extreme problem" categories. Similar to the Luos' study there was a larger difference of median points were seen in similar domains of both tools, i.e. mobility of EQ-5D and physical-functioning of SF-36.

This depicts the validity of the descriptive system as well as the visual analogue scale of the EQ-5D-3L. Hence this strengthens the attempt made by Kularatna et al (2014) is composing population norms specific for Sri Lanka [24].

One limitation of the study includes the gathering of re-test responses for the reliability analysis by contacting the participants after 12 hours from the initial administration of the questionnaire. Hence the potential of previous answers influencing the provision of newer answers could not be totally excluded. This is because the EQ-5D-3L captures the QOL "at the time of completion" [16]. If the re-data collection was done on a later day, the constructs of the QOL may get changed. Hence this was the best possible option for the test-retest method.

Another limitation is the non-availability of the characteristics of the patients. Literature is available in which these two tools have been used in measuring the validity, for many other disease conditions with participants comprising of diverse characteristics [24, 2628]. However policy-wise the age-groups of the two institutions are similar. Furthermore there were no restrictions related to gender or any other characteristic in accessing care in both these settings. Hence, except for the disease-condition related parameters, the characteristics of the study samples from both settings could be assumed to be more or less similar.

\section{Conclusions and Recommendations}

EQ-5D-3L questionnaire demonstrates construct validity, and is a reliable tool in measuring QOL among stroke survivors.

\section{Author declarations}

Competing interests: The authors declare that they have no conflict of interests.

Ethics, consent and permissions: Ethics approval was obtained from the Ethics Review Committee of Medical Research Institute (Reference number: 60/2014) prior to the data collection. Informed written consent was obtained from the participants.

\section{Consent to publish}

The manuscript does not depict any individual data.

\section{Funding}

None.

\section{Acknowledgements}

Authors like to acknowledge the EuroQol group for providing the translated EQ-5D-3L questionnaire and the UK-TTO dataset free of charge (Registration ID: 6554).

Author contribution: PKBM was the principal investigator and MWG and SJ were supervisors. PKBM, MWG and SJ developed the methodology. SMA, SS, CS and LSDS were involved in refining the methodology. All authors were 
involved in planning the analysis. PKBM drafted the manuscript. All authors read and approved the final manuscript.

\section{References}

1. Zhong W, Geng N, Wang P, Li Z, Cao L. Prevalence, causes and risk factors of hospital readmissions after acute stroke and transient ischemic attack: a systematic review and meta-analysis. Neurol Sci 2016; 37(8): 1195-1202.

2. Colaianni V, Mazzei R, Cavallaro S. Copy number variations and stroke. Neurol Sci 2016; 37(12): 1895-1904.

3. McKay J, Mensah GA, Mendis S, Greenlund K. The Atlas of Heart Disease and Stroke. Geneva/: World Health Organization; 2004. http://www.who.int/iris/handle/10665/ 43007.

4. Corbyn Z. Stroke - Statistics: A growing global burden. Nature 2014; 510(7506): S2-S3.

5. Mukherjee D, Patil CG. Epidemiology and the global burden of stroke. World Neurosurg 2011; 76 (6 SUPPL.).

6. Engelgau M, Okamoto K, Navaratne KVGS. Prevention and Control of Selected Chronic NCDs in Sri Lanka: Policy Options and Action. Health, Nutrition and Population Family. Human Development Network: World Bank; 2010. http://hdl.handle.net/10986/13607.

7. Mahesh PKB, Gunathunga MW, Jayasinghe S, Arnold SM, Haniffa R, De Silva AP. Pre-event quality of life and its influence on the post-event quality of life among patients with ST elevation and non-ST elevation myocardial infarctions of a premier province of Sri Lanka. Health Qual Life Outcomes 2017; 15(1): 154.

8. Wijeratne T, Gunaratne P, Gamage R, et al. Stroke care development in Sri Lanka: The urgent need for neurorehabilitation services. Neurol Asia 2011; 16(2): 149-51.

9. TC, SG, CA. Epidemiology of stroke in the district of Colombo, Sri Lanka: A community-based study. Cerebrovasc Dis 2011; 32: 6.

10. Mahesh PKB, Gunathunga MW, Jayasinghe S, Arnold SM, Liyanage SN. Factors influencing pre-stroke and poststroke quality of life among stroke survivors in a lower middle-income country. Neurol Sci 2018; 39(2): 287-95.

11. Ware JE, Gandek B, Guyer R, Deng N. Standardizing disease-specific quality of life measures across multiple chronic conditions: development and initial evaluation of the QOL Disease Impact Scale $\left(\right.$ QDIS $\left.^{\circledR}\right)$. Health Qual Life Outcomes 2016; 14(1): 84.

12. Frendl DM, Ware JE. Patient-reported Functional Health and Well-Being Outcomes With Drug Therapy. Med Care 2014; 52(5): 439-45.

13. Kotecha D, Ahmed A, Calvert M, Lencioni M, Terwee CB, Lane DA. Patient-Reported Outcomes for Quality of Life Assessment in Atrial Fibrillation: A Systematic Review of Measurement Properties. Quinn TJ, ed. PLoS One 2016; 11(11): e0165790.

14. Mallawarachchi DSV. Quality of Life of Stroke Patients Presenting to Selected Hospitals in the Colombo District and the Possibility of Common Mental Disorders among the Principal Informal Caregivers. MD Community Medicine, Post Graduate Institute of Medicine, University of Colombo. 2007.

15. Ware JE, Snow KK, Kosinski M, Gandek B. SF-36 Health Survey Manual and Interpretation Guide. Bost New Engl Med Cent. 1993: 1 v. (various pagings).

16. Reenen M, Oppe M. EQ-5D-3L User Guide. EuroQol Research Foundation: Netherland; 2015.

17. Mahesh PKB, Gunathunga MW, Jayasinghe S, et al. Financial burden of survivors of medically-managed myocardial infarction and its association with selected social determinants and quality of life in a lower middle income country. BMC Cardiovasc Disord 2017; 17(1): 251.

18. Wells GA, Russell AS, Haraoui B, Bissonnette R, Ware CF. Validity of Quality of Life Measurement Tools - From Generic to Disease-specific. J Rheumatol Suppl 2011; 88: 2-6.

19. Muller AE, Skurtveit S, Clausen T. Validating the generic quality of life tool "QOL10" in a substance use disorder treatment cohort exposes a unique social construct. $B M C$ Med Res Methodol 2016; 16(1): 60.

20. Lin XJ, Lin IM, Fan SY. Methodological issues in measuring health-related quality of life. Tzu Chi Med J 2013; 25(1): 8-12.

21. Thorvaldsen P, Kuulasmaa K, Rajakangas AM, Rastenyte D, Sarti C, Wilhelmsen L. Stroke trends in the WHO MONICA project. Stroke 1997; 28(3): 500-6.

22. Chang HH, Chie WC, Chin YH, Hsu CP, Liu TW, WhangPeng J. Development and validation of an instrument for the measurement of health-related quality of life based on view of traditional chinese medicine perspective. $J$ Tradit Complement Med 2012; 2(4): 295-300.

23. Kularatna S, Whitty JA, Johnson NW, Jayasinghe R, Scuffham PA. EQ-5D-3L Derived Population Norms for Health Related Quality of Life in Sri Lanka. Bammann K, ed. PLoS One 2014; 9(11): e108434.

24. Luo N, Chew LH, Fong KY, et al. Validity and Reliability of the EQ-5D Self-report Questionnaire in Chinesespeaking Patients with Rheumatic Diseases in Singapore. Ann Acad Med Singapore 2003; 32(5): 685-90.

25. Myers C, Wilks D. Comparison of Euroqol EQ-5D and SF-36 in patients with chronic fatigue syndrome. Qual Life Res. 1999; 8(1-2): 9-16.

26. Cleemput I, Kesteloot K, Moons P, et al. The construct and concurrent validity of the EQ-5D in a renal transplant population. Value Heal. 2004; 7(4): 499-509.

27. Batt K, Recht M, Cooper DL, Iyer N, Kempton C. Construct validity of patient-reported outcome instruments in US adults with hemophilia: results from the Pain, Functional Impairment, and Quality of life (P-FiQ) study. Patient Prefer Adherence 2017; 11: 1369-80.

28. Aranda-Jan CB, Mohutsiwa-Dibe N, Loukanova S. Systematic review on what works, what does not work and why of implementation of mobile health (mHealth) projects in Africa. BMC Public Health 2014; 14(1): 188. 